\title{
Does Organisational Climate Improve Quality Management Practice? Empirical Evidence from Egyptian Higher Education
}

\author{
Shorouk Mohamed Farag Mohamed Aboudahr*, Mua'azam Bin Mohamad \\ School of Education and Modern Languages, Universiti Utara Malaysia, Malaysia
}

Received August 8, 2020; Revised September 27, 2020; Accepted October 24, 2020

\section{Cite This Paper in the following Citation Styles}

(a): [1] Shorouk Mohamed Farag Mohamed Aboudahr, Mua'azam Bin Mohamad, "Does Organisational Climate Improve Quality Management Practice? Empirical Evidence from Egyptian Higher Education," Universal Journal of Management, Vol. 8, No. 6, pp. 296 - 305, 2020. DOI: 10.13189/ujm.2020.080602.

(b): Shorouk Mohamed Farag Mohamed Aboudahr, Mua'azam Bin Mohamad (2020). Does Organisational Climate Improve Quality Management Practice? Empirical Evidence from Egyptian Higher Education. Universal Journal of Management, 8(6), 296 - 305. DOI: 10.13189/ujm.2020.080602.

Copyright $\subseteq 2020$ by authors, all rights reserved. Authors agree that this article remains permanently open access under the terms of the Creative Commons Attribution License 4.0 International License

\begin{abstract}
This study investigated the influence of organizational climate on quality management practices in Egyptian public universities. The study used a quantitative research design method. The sample consists of 150 respondents selected through both stratified sampling and simple random sampling to get a real population representation and minimization of the sampling bias. The research used the questionnaire as an instrument that involved 23 items, distributed to four disciplines: staff freedom, resource adequacy, decision making participation, and quality management practice for data collection by the researcher. The instrument was validated by experts from the Department of Education, Utara Malaysia University, through the face and content validation. Data collected were analyzed using Structural Equation Modelling (SEM) which was employed for data analysis method through AMOS statistical software based on the parametric SEM in AMOS 22.0. Findings from the study revealed that resource adequacy has a significant and positive effect on quality management practices. Meanwhile, decision-making participation has no significant effect on quality management practices. Furthermore, the study indicates that male academic staffs have a significantly higher level of organizational climate than female academic staffs in the Egyptian Higher institution. It was recommended that the university management systems be developed and it is the climate in the light of quality management stander and giving academic staff a clear role
\end{abstract}

in expressing their opinion as conducting discussion plans on decision making with the participation of all employees' levels at the university.

Keywords Organizational Climate, Quality Management Practice, Higher Education, Egyptian

\section{Introduction}

Higher education is a powerful mechanism for development, poverty reduction, and a shared prosperity boost in every country of the world (World Bank, 2017). The global student participation in tertiary education is increasing rapidly (Marginson, 2016; UNESCO 2015; Williams et al. 2015), meanwhile, a number of environmental forces are driving changes within and across countries and their higher education. Consequently, to remain viable in the changing labor market, the higher education institutions (HEIs) need to change their degree programs and courses (Orbeta, Gonzales, and Cortes, 2016). However, the preservation of high-quality standards in education has become a major concern of HEIs and governments around the world which the Egyptian education institutions are not exempted. This requires a suitable climate for practicing quality management to ensure it is successful in schools, universities, and other 
educational institutions in Egypt (Ackah-Jnr \& Danso, 2019).

The higher education sector faces several issues in the Middle East, most especially in Egypt, the challenges include inadequate financial resources, huge demographic pressure, weakness of administrative leadership, and limited management practices on the educational system as well as weak institutions emanating from huge dishonesty which revolves around the education system (Dahdouh, 2019 \& Eltemamy, 2018). Similarly, Ghabbour (2012) indicates that Egyptian universities face challenges that impose on them to change their nature and traditional way of work in the area of management, education, and university structures. In spite of the increasing interest in achieving the quality of higher education, the reality in higher education institutions suffers several setbacks that prevent the development processes, the creation of climate, leadership, and a supportive environment for development (Al-barbari, 2016). In addition, higher education institutions in Egypt encountered challenges and obstacles for which it is necessary to practice a lot of effort to develop and renew performance and increase its effectiveness in order to achieve the core objectives and increase competitiveness which helps to distinguish the universities (Al- Degdg, 2016).

In 2016, the cabinet of ministers for 2030 strategic vision for education in Egyptian higher institution aims to activate the rules of accreditation and quality in line with international standards, and developing the capabilities of faculty leaderships; develop the organizational structure of the Ministry and higher education institutions to achieve flexibility, responsiveness, and quality of education. In the light of this, Donina, Meoli \& Paleari, (2015); Guo, (2016), and Ursin (2019) emphasized that reform of the higher education system has become one of the issues that haunt everyone since education reform needs a holistic view of all components of the educational system. It should be based on the availability of quality in these various components, from there Egypt is interested in applying quality management in the higher education system and its importance for improving institutional goals. Hence, organizational climate is considered one of the most important organizational variables needed for organizations to succeed in achieving their goals in order to practice quality management in their institutions (Shanker et al, 2016). Furthermore, studies have confirmed that the organizational climate prevailing in the organization is reflected in the effectiveness of this organization in achieving its goals.

The literature on organizational climate suggests that successful implementation of quality management practice mostly depends on a work climate conducive to innovation (Al- Subai, 2014; Budihardjo, 2014). Hence, this study intends to investigate the nature of the organizational climate prevailing in some Egyptian universities and work to improve it in line with the goals of the university in achieving a high level of quality practice that cannot be achieved without an organizational climate that helps motivate and encourage employees to achieve success for the sake of outstanding performance by answering questions, Therefore, the research represented by the following objectives:

1. To examine the influence of organizational climates and quality management practices of academic staffs in the Egyptian higher education institution.

2. To examine the significant difference in the level of organizational climate based on the gender of lecturers in Egyptian higher education institutions.

\section{Literature Review and Hypothesis}

Prior studies focused mainly on individual and uncommon aspects of organizational elements. Accordingly, the current study identifies the relationship between organizational climate and quality management practice public in higher education institutions. According to Parke and Seo (2017), the organizational climate represents the internal work environment in its various aspects, characteristics, and interactions, by which the organizational climate plays a major role in stabilizing the ethical and job behavior of working individuals in terms of forming and adjusting values, cultures, and attitudes in the educational institution (Wong et al, 2019). It is also clear that the organizational climate represents the personality of the organization in all its dimensions, as well as the organization's success in creating a suitable climate for employees that would encourage the creation of a meaningful working environment for all employees.

Al Shobaki et al (2018) hinted that as individuals in the effective organizational environment feel their importance at work and their ability to participate in decision-making and contribute to the formulation of policies and organizational plans, and a feeling of trust prevails between management and subordinates. Similarly, Salisu, Chinyio \& Suresh (2015); Schreurs et al (2015) confirmed that organizational climate in any establishment determines the areas of satisfaction and dissatisfaction of employees thus, facilitates the administration to create more interaction in the workplace and hence improve productivity.

As demonstrated by Al Shobaki et al (2018) climate has a great important role in higher education institutions due to its prominent role in achieving employee satisfaction and development process, implying that organizations care to study their internal environment and work to develop and improve them in order to achieve advanced levels of quality. Considering the fact that the effectiveness of the organization depends on the nature of the organizational climate prevailing in them (Al Damoe, Hamid \& Sharif, 2017). In the context of the above, Johnson, Stevens (2007) recommended in their study that 
SLEQ consider as a significant tool to examine teachers' perceptions of school climate for student achievement.

Importantly, however, the factor of the organizational climate helps to support and practice quality management at higher education as well as create a positive environment for fulfilling the institution's goals. Meanwhile, Purvis, Zagenczyk, and McCray (2015) implied that the importance of organizational climate has emerged through its active role in the organization's success or failure. Organizational climate has a significant impact on the attitudes of employees, their motivation, satisfaction with work, and consequently their behavior and performance (Budihardjo, 2014). The organizational climate can be conceptualized through the perception of employees in an institution's supervision, communication. Therefore, organizations are seeking to study the internal environment and work to develop them to achieve advanced levels of quality, considering that the effectiveness of the organization depends on the nature of the organizational climate prevailing in it (Al- Subai, 2014).

\subsection{Organizational Climate and Quality Management Practices}

Notable previous studies result presented that quality initiatives without considerate an organizational climate are permanently disposed to failure. A brief review was conducted of the organizational climate and quality management research and noted that little was done to linking between organizational climate and quality management practice in the Arab world most especially in Egypt. Bellou and Andronikidis (2009) the findings of their studies found that quality service was affected by organizational climate. Similarly, Budihardjo (2014) conducted a study to determine the effect of the organizational climate on achieving the quality of higher education institutions in Algeria and the study found that organizational climate has a great impact on the achievement of the high quality of education. Also, Jones and Seraphim (2008) study aimed to know the differences from the point of view of 8126 workers in the US government about the quality culture and the organizational climate. The study found a positive relationship between the work environment and the spread of quality culture.

The result of Jones and Seraphim (2008) is the same with Ibraheem (2012) which was conducted to identify the role of organizational climate in the diffusion of quality culture among academic staff at Al-Azhar university. Likewise, Hewett and La Paro (2020) Based on their work on organizational climate: collegiality and supervisor support in early childhood education programs. The study found the importance of the organizational climate to program quality. Dennis and O'Connor (2013) in their study investigated the relationships between organizational climate, perception of teachers toward work environment, and quality of classroom. They found a significant relationship between overall organizational climate and classroom quality. Furthermore, Malloy et al (2015) the purpose of their study to measure the impact of organizational climate on quality and found organizational climate has an appositive impact on the quality of teacher implementation of positive action.

While higher education institutions in Egypt did not reach the levels of quality management practice, this explains the continuous decline in the global ranking of higher education institutions in Egypt. Despite attempts to reform and implement quality, officials have overlooked an important aspect which is improving the prevailing organizational climate, implying that the organizational climate has a clear impact on achieving quality management in public universities in Egypt (Ibraheem, 2012). Several studies mentioned dimensions of organizational climates. This dimension includes students' supports, affiliation, professional interest, staff freedom, participatory decision making, innovation, resource adequacy, and work pressure (Al Damoe, Hamid \& Sharif, 2017; Al Shobaki et al, 2018; Castro \& Martins, 2010; Goleman, 2000). However, the recommendation of the previous studies emphasized the three major dimensions in the western world (staff freedom, resources adequacy, and decision making participation). Therefore, this study replicates these three-dimensions in Egypt higher education to examine quality management practice.

Furthermore, the prior studies on organizational climate in the education sector have identified the impact of organizational climate dimension on achieving the quality of educational institutions related to gender and work experiences. However, research has been conducted on the organizational climate in higher education this research found inconsistent findings in their several research. For instance, Mahasneh Gazo and Al-Adamat (2019) indicated a study to know the level of organizational climate prevailing in the colleges of Kuwait University and its effect on leadership support, it was found that there are no statistically significant differences in the dimensions of the organizational climate due to gender.in the same vein, Ashory (2017); Aobidah (2016) in their study found that there are no statistically significant differences in the dimensions of the organizational climate due to gender. Whereas, Al-Muasher (2001; Al-Subaie (2014) and Ibraheem (2012) found there are statistically significant differences in the dimensions of the organizational climate due to gender.

\section{Materials and Method}

This study examines the relationship between organizational climate and gender affiliation on quality management practices in the Egyptian education sectors. 
The study looks at the organizational climate in the area of staff freedom, resource adequacy, and decision-making participation. Using a positivist research attitude, this study is based on primary data sources, quantitative in nature, and has a deductive research approach. It is a cross-sectional study, and data were collected using questionnaires. Figure 1 below indicated the theoretical framework of the relationship between organizational climates and quality management practices.

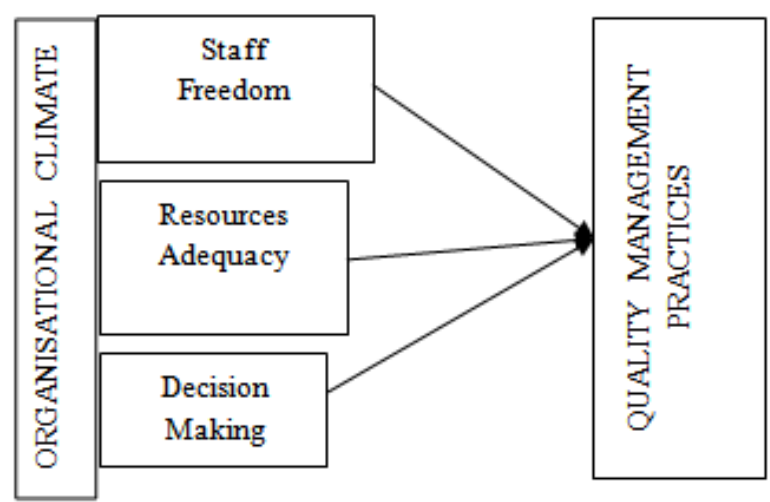

Figure 1. Theoretical Framework

The current study focused on the organizational climate associated with quality management practices of higher education in Egypt. Hence the target population of this study comprises 150 lecturing staffs employed. These academic staffs include Teaching Assistant, Assistant Lecturer, lecturers, assistant professors, associate professors, and professors. As there is an unequal number of academic staff engaged from different institutions, the study used both stratified sampling and simple random sampling to get a real population representation and reduce the bias of the sampling. Meanwhile, the questionnaire for data collection was designed to measure the variables of the study. The questionnaire was validated via in pilot study. First is the content, based on the expert evaluation, by face validity (Shkeer\&Awang, 2019a; Bahkia et al., 2019). Content validity also acts as a consultation process for small samples and/or expert panels to determine the suitability of the items selected to test a construct (Hair et al., 2007; Sekaran \& Bougie, 2010). Second, construct validity, this includes an exploratory factor analysis using the PCA, and rotations of varimax were carried out to determine the validity of the construct. In the meantime, factor analysis was carried out to verify the scale and determine the degree to which the data met the study structure. Also, researchers employed the Cronbach Alpha to quantify the reliability of the questionnaire. The table below shows the results of the reliability and validity test.

The survey instruments are classified into two major sections. The first is the demographical information which includes gender, age, name of the university, and academic qualification among others. Whereas, the second section is the main variable which is comprised of organizational climate (Staff freedom 6 items; resources adequacy 7 items; and decision making participation 6 items) and quality management practices (7 items). Each measurement scale measured the result by assessing how strongly the subject agrees or disagrees with the statement on a 5 point Likert scale based on the interval scale.

Statistics packages of SPSS were used for organizing data collecting from respondents as well as to run a pilot study due to coniform the validity and reliability of the study. While Structural Equation Modelling (SEM) was employed for data analysis method through AMOS statistical software based on the parametric SEM in AMOS 22.0. The analysis model is comprised of the measurement model and the structural model. In the measurement model, validity (convergent, construct, and discriminant) and reliability (composite reliability) of the constructs were analyzed through confirmatory factor analysis (CFA). Once the reliability and validity of the measurement model were accomplished, the structural model was used for empirical hypotheses testing in the study. Finally, the independent sample T-test was used to examine the level of organizational climate based on the gender of lecturers in the Egyptian higher institution.

Table 1. Summary of Items for Each Instrument, Validity, and Reliability Coefficient

\begin{tabular}{|c|c|c|c|c|}
\hline $\mathrm{S} / \mathrm{N}$ & Constructs & Items & $\begin{array}{c}\text { Validity } \\
(\mathrm{KMO})\end{array}$ & $\begin{array}{c}\text { Reliability } \\
(\alpha)\end{array}$ \\
\hline 1 & $\begin{array}{c}\text { Quality } \\
\text { Management } \\
\text { Practices }\end{array}$ & 7 & 0.641 & 0.752 \\
\hline 2 & Staffs Freedom & 16 & 0.707 & 0.774 \\
\hline
\end{tabular}

In Table 1, according to the test, all the tests have been found to have reliability ranging from 0.752 to 0.774 . Following the norm, an instrument with a coefficient of 0.60 is considered to have acceptable reliability; whereas a coefficient of 0.70 and above indicates a high degree of reliability of the instrument (Hair et al., 2006; Nunnally,\& Bernstein, 1994; Sekaran \& Bougie, 2010). Therefore, it has been found that all the tests have a high standard of validity ranging from 0.641 to 0.707 . Following the norm, an instrument with a factor loading above 0.3 is considered to meet a minimum point, loading above 0.4 is considered to be more important and above 0.5 is considered to be practically relevant (Awang,2010; 2012 \& Noor et al., 2015).).Based on the validity test, out of the 26 items, 3 items were deleted because of cross-loading in another component.

\section{Analysis and Results}

Out of 150 questionnaires distributed to the academic staff at the Egyptian University, 132 questionnaires were returned representing an $88 \%$ response rate. Six cases of questionnaires were excluded due to the issue of outliers (both univariate and multivariate outliers). Finally, 126 
(84\%) questionnaires were retained for further analysis. Meanwhile, confirmatory Factor Analysis (CFA) validates the instrument by evaluating the constructs in terms of reliability, validity, and uni-dimensionality (Awang, 2015; Awang, Afthanorhan \& Mamat, 2016). After completion of the exploratory factor analysis (EFA) method, the field study was conducted using a set of construct items. Any factor loading below the rule of thumb was removed and objects were assembled into their relevant components. In addition, the field study data were used to authenticate the constructs' measurement model. Considering CFA, the reliability of instruments is mainly examined using a composite reliability index, while construct validity that happens to be the main validity measure in CFA is comprised of convergent and discriminant validity (Awang, 2012).

Table 2. Summary of the Measurement Model (Construct Validity and Indicator Reliability)

\begin{tabular}{|c|c|c|c|c|}
\hline Constructs & Items & $\begin{array}{c}\text { Factor } \\
\text { Loading }\end{array}$ & $\begin{array}{c}\text { CR (> } \\
0.6)\end{array}$ & $\begin{array}{c}\mathrm{AVE}(> \\
0.5)\end{array}$ \\
\hline \multirow{7}{*}{$\begin{array}{c}\text { Quality } \\
\text { Management } \\
\text { Practices }\end{array}$} & QMP1 & 0.92 & \multirow{7}{*}{0.920} & \multirow{7}{*}{0.639} \\
\hline & QMP2 & 0.92 & & \\
\hline & QMP3 & 0.86 & & \\
\hline & QMP4 & 0.85 & & \\
\hline & QMP5 & 0.95 & & \\
\hline & QMP6 & 0.45 & & \\
\hline & QMP7 & 0.46 & & \\
\hline \multirow{5}{*}{ Staffs Freedom } & SF1 & 0.96 & \multirow{5}{*}{0.865} & \multirow{5}{*}{0.573} \\
\hline & SF2 & 0.92 & & \\
\hline & SF3 & 0.55 & & \\
\hline & SF4 & 0.60 & & \\
\hline & SF5 & 0.66 & & \\
\hline \multirow{5}{*}{$\begin{array}{l}\text { Resources } \\
\text { Adequacy }\end{array}$} & RA1 & 0.23 & \multirow{5}{*}{0.804} & \multirow{5}{*}{0.515} \\
\hline & RA2 & 0.21 & & \\
\hline & RA5 & 0.94 & & \\
\hline & RA6 & 0.93 & & \\
\hline & RA7 & 0.86 & & \\
\hline \multirow{6}{*}{$\begin{array}{c}\text { Decision Making } \\
\text { Participation }\end{array}$} & DMP1 & 0.26 & \multirow{6}{*}{0.839} & \multirow{6}{*}{0.516} \\
\hline & DMP2 & 0.77 & & \\
\hline & DMP3 & 0.92 & & \\
\hline & DMP4 & 0.87 & & \\
\hline & DMP5 & 0.87 & & \\
\hline & DMP6 & 0.80 & & \\
\hline
\end{tabular}

The survey instruments used in this study comprises of one dependent constructs with three dimensions and one independent constructs. The organizational climate (staff freedom, resources adequacy, \& decision making participation) considered as an exogenous construct, and the quality management practices are endogenous constructs. Therefore, Table 2 indicated the finding of the measurement model where the convergence validity and composite reliability were assessed. The result shows the value of factor loading, AVE, and composite reliability where the report of this study revealed the adequate factor loadings of all items (above the threshold value of 0.6 ) unless for three items that were excluded due to low factor loading. As indicated in Table 2:

In the Confirmatory Factor Analysis (CFA) results, the reported indicated that the model was adequate for further analysis. CFA results show that the RMSEA $=.079$, GFI $=.890, \mathrm{CFI}=.895, \mathrm{TLI}=.927, \mathrm{NFI}=.888$, and $\chi 2 / \mathrm{df}=$ 3.126 . Only GFI and $\chi 2 / \mathrm{df}$ met the essential level, but other indicators failed to reach the minimum level. These findings showed that the absolute fit index and incremental index for the pooled constructs did meet the necessary level, which demonstrates the achievement of model fit indices. To fulfill fitness indices, certain modifications were essential in the model. Via CFA, the study questionnaire was considered valid and reliable and could be used for testing the empirical hypotheses. See Table 3.

\subsection{Assessment of the Structural Model}

Figure 2 has shown the structural model which reveals the causal effects of organizational climate predictor on the independent variable. It was found that the proposed model explained a highly significant percentage of the variance in quality management practices (44\%). Cohen (1988) claims that R2 exceeding $26 \%$ is recognized to have a great influence on a causal model. Therefore, the current model that is comprised of evaluating the level of organizational climate is meaningful and sufficient since it contributes a high impact on the research on quality management practices. The result of the structural model is indicated in Figure 2 and Table 3.

Table 3. Model Fits (After deleting low factor loading items)

\begin{tabular}{|c|c|c|c|c|}
\hline S/N & Name of Category & Index Value & Threshold & Remarked \\
\hline \multirow{2}{*}{1} & \multirow{2}{*}{ Absolute fit } & RMSEA $=.079$ & RMSEA $<.08$ & The required level is accomplished \\
& & GFI $=.890$ & GFI $>.90$ & The required level is accomplished \\
\hline \multirow{2}{*}{2} & Incremental fit & CFI $=.895$ & CFI $>.90$ & The required level is accomplished \\
& & $\mathrm{TLI}=.927$ & $\mathrm{TLI}>.95$ & $\begin{array}{c}\text { The required level is accomplished } \\
\text { The required level is accomplished }\end{array}$ \\
\hline \multirow{2}{*}{3} & Parsimonious fit & $\mathrm{X}^{2} / \mathrm{df}=3.126$ & $\mathrm{NFI}<.90$ & The required level is accomplished \\
\hline
\end{tabular}




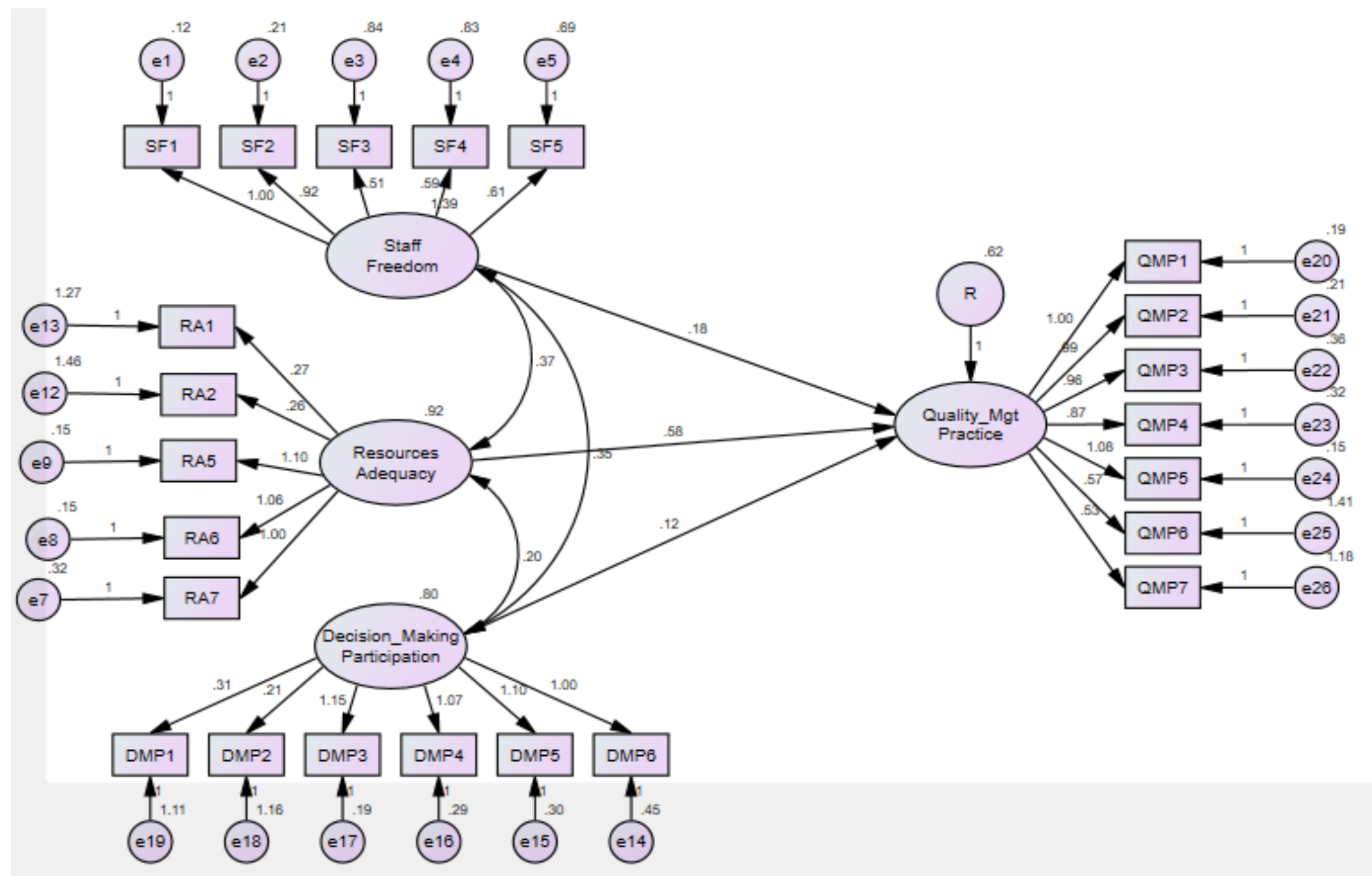

Figure 2. Assessment of the Structural Model 
Table 4. Result of the Structural Model (Testing of Hypotheses)

\begin{tabular}{|c|c|c|c|c|c|c|}
\hline 6Hypotheses & & & Estimate & S.E. & C.R. & P \\
\hline Quality Mgt. Practice & $<---$ & Staff Freedom & .182 & .063 & 2.872 & .004 \\
\hline Quality Mgt Practice & $<---$ & Resources Adequacy & .583 & .082 & 7.136 & $* * *$ \\
\hline Quality_Mgt_Practice & $<---$ & Decision_Making_Participation & .118 & .081 & 1.450 & .147 \\
\hline
\end{tabular}

Table 5. Significant Differences in the Level of Organizational Climate Based on the Gender of Lecturers

\begin{tabular}{|c|c|c|c|c|c|c|c|c|}
\hline & & & & \multicolumn{2}{|c|}{ Test Statistics } & Means & \\
\hline $\begin{array}{c}\text { Hypo-thesis } \\
\text { No }\end{array}$ & $\begin{array}{c}\text { Latent } \\
\text { Construct }\end{array}$ & $\begin{array}{c}\text { Male \& } \\
\text { Female }\end{array}$ & $\mathrm{N}$ & $\begin{array}{c}\text { Mann- } \\
\text { Whitney } \\
\text { U Test }\end{array}$ & Z Score & $\begin{array}{c}\text { Asymp. } \\
\text { Sig. }\end{array}$ & Median & Decision \\
\hline H4 & $\begin{array}{c}\text { Organizati } \\
\text { on Climate }\end{array}$ & $\begin{array}{c}\text { Male } \\
\text { Female } \\
\text { Total }\end{array}$ & $\begin{array}{c}74 \\
51\end{array}$ & 7818.500 & -2.303 & $0.021^{* *}$ & $\begin{array}{c}3.244 \\
2.757\end{array}$ & Support \\
\hline
\end{tabular}

Note: ${ }^{* * *}$ p-value @1\% and ${ }^{* *}$ p-value @ 5\% significant level.

The phase of hypotheses testing was done using structural equation modeling after the validating of the measurement model. The study tested a significant relationship between organizational climate and quality management practices in Egyptian higher institutions with three sub-hypotheses (staff freedom, resources adequacy, and decision making participation). Table 4 shows the path coefficients, standard error, and p-values of the relationship between constructs presented in the quality management practices model. Findings, presented in Table 4, supported H1 $(\beta=.182, \mathrm{SE}=.063, \mathrm{p}=.004$ $<.01$ ), which stated that there was a significant and positive effect of staff freedom on quality management practices. Findings also supported $\mathrm{H} 2(\beta=.583, \mathrm{SE}=.082$, $\mathrm{p}=.000<.01$ ), which concluded that there was a significant and positive effect of resources adequacy on quality management practices. However, results supported H3 $(\beta=.118, \mathrm{SE}=.081, \mathrm{p}=.147<.01)$, which was interpreted as decision making participation having no significant effect on quality management practices. The overall result of the study indicates that organizational climate has a significant influence on quality management practices in the area of staff freedom and resource adequacy. Thus, creating an enabling environment for the academic staff by making provision for adequate resources and giving them freedom for training, research, and development.

\subsection{Significant Differences in the Level of Organizational Climate Based on Gender of Lecturers in Egyptian Public University}

This section adopts the Mann-Whitney U Test to test the Hypothesis H1, as stated in the research objective. It shows differences between the environmental friendliness of male and female lecturers. Mann-Whitney U test determines the ranks for two or more groups i.e, it describes the direction of the differences between two or more groups and the effect sizes (Pallant, 2010). As stated in the research hypothesis, "significant differences in the level of organizational climate based on the gender of lecturers in Egyptian public university” the Mann-Whitney U Test was used to test the differences between the two groups. Table 4 determines the direction of differences between the male and female academic staff towards the organizational climates at Egyptian University.

The study determines which groups between the male and female academic staffs have a higher level of access to enabling environment towards quality management practice in response to the Hypothesis H4. The result of the study indicates that male academic staffs have a significantly higher level of organizational climate than female academic staffs in the Egyptian Higher institution”. The Mann-Whitney U Test reports the median value for each group. The organizational climate average value of male academic staff is $(M=3.24)$ and the female academic staff $(F=2.76)$. The test of the Mann-Witney $U$ shows the results of male academic staffs $(\mathrm{Md}=3.24, \mathrm{n}=$ $74)$ and female academic staffs ( $\mathrm{Md}=2.76, \mathrm{n}=51)$ with $\mathrm{U}=7818.500, \mathrm{z}=-2.303, \mathrm{p}=0.021$ and $\mathrm{r}=0.083$. The effect size statistics (r) is the total value of $\mathrm{z}$ statistics divide by the square root of the total number of respondents $(\mathrm{N})$ (i.e., $\mathrm{r}=\mathrm{z} / \sqrt{\mathrm{N}}$ ). Hence, $\mathrm{z}=-2.303, \mathrm{~N}=$ 126. Therefore, the effect size is 0.083 . According to (Cohen, 1988) the criteria for the effect size is as follow: $0.1=$ small size; $0.3=$ medium size and $0.5=$ large size . Therefore, the effect size (r) is a small effect. The result revealed that male academic staffs have access to the enabling environment in terms of staff freedom and little available resources than female academic staff in Egypt. Hence, the University authority needs to make an adequate enabling environment for both male and female academic staff to enhance better quality management.

\section{Discussion}

This study aims to examine the influence of organizational climate on quality management practice in a public university in Egypt. The overall result of the 
study indicates that organizational climate has a significant influence on quality management practices in the area of staff freedom and resource adequacy. The finding of the study agreed with the finding of prior studies such as Al Shobaki et al, 2018; Budihardjo, 2017; Bellou \& Andronikid, 2009; Dennis \& O'Connor, 2013; Hadiyanto, 2018; Hewett \& La Paro, 2020; Ibraheem, 2012; Malloy, 2015; Syahril \& Hadiyanto, 2019). Moreover, the result of decision making participation was no significant effect on quality management practices contrary to a study conducted by (Hewett \& La Paro, 2020; Dennis \& O'Connor, 2013) who found decision making is the most important factor among academic staff and their principal in the institution in order to create a positive climate that might influence quality management practices. Thus, creating an enabling environment for the academic staff by making provision for adequate resources and giving them freedom for training, decision making, research, and development.

Furthermore, the result of the study indicates that male academic staffs have a significantly higher level of organizational climate than female academic staff in the Egyptian university. The finding consistent with studies conducted by (Ghanbouti, 2009 \& Ibraheem, 2012) which result in there is statistically significant differences in the dimensions of the organizational climate due to males. However, the result is different from the study by (Aobidah, 2016; Ashory, 2017; Al-Azmy, 2019) which found there are no statistically significant differences in the dimensions of the organizational climate due to gender Also different from the study by (Al-Subaie, 2014; AlMuasher, 2001) their study found there are statistically significant differences in the dimensions of the organizational climate due to gender. Hence, the University authority needs to make an adequate enabling environment for both male and female academic staff to enhance better quality management. The difference between the results of previous studies might be due to different environment or policies used in universities around the world.

Based on the finding of this study, the study suggested that lecturers should be involved in decision making that belongs to their department, college, and policymakers taking their suggestions that seek to create a suitable climate that assists all employees to improve quality management practices. Additionally, developing university management systems and it is the climate in the light of quality management stander and giving academic staff a clear role in expressing their opinion as conducting discussion plans on decision making with the participation of all employees levels at the university.

In conclusion, the organizational climate plays a major factor in the organizational climate which helps to support and practice quality management at higher education as well as create a positive environment for fulfilling the institution's goals. It is also clear that the organizational climate represents the personality of the organization in all its dimensions, as well as the organization's success in creating a suitable climate for employees that would encourage the creation of a meaningful working environment for all employees and improve productivity.

\section{REFERENCES}

[1] Ackah-Jnr, F. R., \& Danso, J. B. (2019). Examining the physical environment of Ghanaian inclusive schools: how accessible, suitable and appropriate is such environment for inclusive education?. International Journal of Inclusive Education, 23(2), 188-208.

[2] Al Damoe, F. M., Hamid, K., \& Sharif, M. (2017). The mediating effect of organizational climate on the relationship between HRM practices and HR outcomes in the Libyan public sector. Journal of Management Development, 36(5), 626-643.

[3] Al- Degdg, A. A. M,. (2016). A Suggested Framework for Internationalizing the Egyptian University Education in the Light of International Standards of Universities' Classification. Journal of Faculty of Education - Benha University, 27(108), 327-412. DOI:10.12816/0034527

[4] Al Shobaki, M., Abu-Naser, S. S., El Talla, S. A., \& Amuna, Y. M. A. (2018). Performance Reality of Administrative Staff in Palestinian Universities, International Journal of Academic Information Systems Research, 2(4), 1-17. 2018.

[5] Al- Subai, A,. (2014). The supportive of organizational climate for quality assurance at Majmaah University. Journal of Human and Administrative Sciences, 6, 82-126. DOI:10.12816/003125.

[6] Al-barbari, M, A,. (2016). Developing higher education policies in Egypt to follow the knowledge economy by benefiting from the experiences of Singapore and Malaysia. Journal of Faculty of Education - Benha University, 27(106), 117-244.

[7] Al-Muasher, Z. (2001). The Organizational Climate in Jordanian Universities: A Comparative Study between Public Universities and Private Universities of Some Dimensions of the Current Organizational Climate from the Point of View of the Members of the Administrative Body. Amman, Jordan.

[8] Aobidah, S. M,. (2016). The relationship between the organizational climate and creative behaviour, an empirical study on the faculty intermediate community colleges in Gaza strip. Master Dissertation Presented to the university of Gaza.

[9] Ashory, E,. (2017). The organizational climate impact on the quality of high education institutions in Algeria. Ph. D. Dissertation Presented to the Université de M'sila.

[10] Asnawi, A., Awang, Z., Afthanorhan, A., Mohamad, M., \& Karim, F. (2019). The influence of hospital image and service quality on patients' satisfaction and loyalty. Management Science Letters, 9(6), 911-920. 
[11] Awang, Z. (2010), Research Methodology for Business and Social Sciences. Malaysia: Universiti Teknologi MARA.

[12] Awang, Z. (2012), Research Methodology and Data Analysis. Malaysia: Penerbit Universiti Teknologi MARA Press.

[13] Awang, Z. (2015). SEM made simple: A gentle approach to learning Structural Equation Modeling. MPWS Rich Publication.

[14] Awang, Z., Afthanorhan, A., \& Mamat, M. (2016). The Likert scale analysis using parametric based Structural Equation Modeling (SEM). Computational Methods in Social Sciences, 4(1), 13.

[15] Bellou, V., \& Andronikidis, A. I. (2009). Examining organizational climate in Greek hotels from a service quality perspective. International Journal of Contemporary Hospitality Management.

[16] Berbegal-Mirabent, J. (2013).Doing Research in Business and Management: An Essential Guide to Planning Your Project. Management Decision, 51(6), 1311-1316. Doi.org/10.1108/MD-06-2012-0505

[17] Budihardjo, A. (2014). The relationship between job satisfaction, affective commitment, organizational learning climate and corporate performance. GSTF Journal on Business Review (GBR), 2(4).

[18] Castro, M. L., \& Martins, N. (2010). The relationship between organisational climate and employee satisfaction in a South African information and technology organization. SA Journal of industrial psychology, 36(1), 1-9.

[19] Cohen, J. (1988). Statistical power analysis for the behavioral sciences, 2nd edn. Á/L.

[20] Dahdouh, M, F. (2019,10 October) Our Arab University and the need to build a knowledge society. Turk press. Retrieved from, http://www.turkpress.co/node/40421

[21] Dennis, S. E., \& O'Connor, E. (2013). Reexamining quality in early childhood education: Exploring the relationship between the organizational climate and the classroom. Journal of Research in Childhood Education, 27(1), 74-92.

[22] Donina, D., Meoli, M., \& Paleari, S. (2015). Higher education reform in Italy: Tightening regulation instead of steering at a distance. Higher Education Policy, 28(2), 215-234.

[23] Eltemamy, A. (2018). Developing a programme of support for teacher leadership in Egypt (Doctoral dissertation, University of Cambridge).

[24] Ghabbour (2012). Using knowledge management approach in promoting institutional performance in higher education institutions in Egypt: a proposed perspective. Journal of the Faculty of Education- Ain Shams University: education and psychology, 36(1), 497-584.

[25] Ghanbouti, S,. (2009). The quality of the university climate in some colleges of Sultan Qaboos university from the viewpoint of their students. Education journal, Egypt,12(25), 89-120.

[26] Goleman, D. (2000). Leadership that gets results. Harvard business review, 78(2), 4-17.
[27] Guo, Y,. (2016, May). Study on Reform of China Higher Education Management System. In 2016 International Conference on Economy, Management and Education Technology. Atlantis Press.

[28] Hair, J. F., Money, A. H., Samouel, P., \& Page, M. (2007). Research Methods for Business. Education + Training, 49(4), 336-337. doi: doi:10.1108/et.2007.49.

[29] Hewett, B. S., \& La Paro, K. M. (2020). Organizational Climate: Collegiality and Supervisor Support in Early Childhood Education Programs. Early Childhood Education Journal, 48(4), 415-427.

[30] Ibraheem, A. El,. (2012). The role of the organizational climate in spreading the culture of quality among faculty members at Al-Azhar University colleges in Dakahlia, Education Journal, Benha University, Egypt, 33(89), 1-43. http://srv4.eulc.edu.eg/eulc_v5/libraries/Start.aspx?fn=Vie wSingleSerialPaper\&ScopeID=1.\&item_id $=12274638 \& \mathrm{~Pa}$ perID $=11422353 \& \mathrm{Vol}=23 \& \mathrm{No}=89 \&$ PublishDate $=01 \% 2 \mathrm{f0}$ $1 \% 2 \mathrm{f} 2012$.

[31] Johnson, B., Stevens, J. J., \& Zvoch, K. (2007). Teachers' perceptions of school climate: A validity study of scores from the Revised School Level Environment Questionnaire. Educational and psychological measurement, 67(5), 833-844.

[32] Jones, J. P., \& Seraphim, D. (2008). TQM implementation and change management in an unfavourable environment. Journal of Management Development, 2(3), 291- 306.

[33] Mahasneh, A. M., Gazo, A. M., \& Al-Adamat, O. A. (2019). Cultural Intelligence of the Jordan Teachers and University Students from the Hashemite University: Comparative Study. European Journal of Contemporary Education, 8(2), 303-314.

[34] Malloy, M., Acock, A., DuBois, D. L., Vuchinich, S., Silverthorn, N., Ji, P., \& Flay, B. R. (2015). Teachers' perceptions of school organizational climate as predictors of dosage and quality of implementation of a social-emotional and character development program. Prevention Science, 16(8), 1086-1095.

[35] Marginson, S. (2016). The worldwide trend to high participation higher education: Dynamics of social stratification in inclusive systems. Higher education, 72(4), 413-434.

[36] Noor, N.M., Aziz, A.A., Mostapa, M.R., Awang, Z. (2015), Validation of the Malay version of the inventory of functional status after childbirth questionnaire. BioMed Research International, 2015, 1-10.

[37] Nunnally, J. C., \& Bernstein, I. H. (1994). Psychometric theory (3ed ed.). New York: McGraw-Hill.

[38] Orbeta, A. C., Gonzales, K. G., \& Cortes, S. F. S. (2016). Are higher education institutions responsive to changes in the labor market? (No. 2016-08). PIDS Discussion Paper Series.

[39] Pallant, J. (2010). SPSS survival manual. Sydney. New South Wales, Australia: Allen \& Unwen Press.

[40] Parke, M. R., \& Seo, M. G. (2017). The role of affect climate in organizational effectiveness. Academy of Management Review, 42(2), 334-360. 
[41] Purvis, R. L., Zagenczyk, T. J., \& McCray, G. E. (2015). What's in it for me? Using expectancy theory and climate to explain stakeholder participation, its direction and intensity. International Journal of Project Management, 33(1), 3-14.

[42] Raza, I,. \& Awang, Z,. (2020). Knowledge sharing in multicultural organizations: evidence from Pakistan. Higher Education, Skills and Work-Based Learning. Higher Education, Skills and Work-Based Learning, 10(3), 497-517. Doi.org/10.1108/HESWBL-09-2019-01142020.

[43] Salisu, J. B., Chinyio, E., \& Suresh, S. (2015). The impact of compensation on the job satisfaction of public sector construction workers of jigawa state of Nigeria. The Business \& Management Review, 6(4), 282.

[44] Schreurs, B., Guenter, H., van Emmerik, I. H., Notelaers, G., \& Schumacher, D. (2015). Pay level satisfaction and employee outcomes: the moderating effect of autonomy and support climates. The International Journal of Human Resource Management, 26(12), 1523-1546.

[45] Sekaran, U., \& Bougie, R. (2010). Research for Business-A Skill Building Approach.

[46] Shanker,R., Bhanugopan, R., Van der Heijden, B. L., Farrell, M.(2016). Organizational climate for innovation and organizational performance: The mediating effect of innovative work behavior. Journal of vocational behavior, (100), 67-77.
[47] Shkeer, A.S., \& Awang, Z. (2019a). Exploring Items for Measuring Marketing Information System Construct: An Exploratory Factor analysis. International Review of Management and Marketing, 9(6), 87-97.https://doi.org/10. 32479/irmm.8622.

[48] Syahril, S., \& Hadiyanto, H. (2018). Improving school climate for better quality educational management. Journal of Educational and Learning Studies, 1(1), 16-22.

[49] United Nations Educational, Social and Cultural Organization (UNESCO).(2015). UNESCO Institute for Statistics data on education. http://data.uis.unesco.org/

[50] Ursin, J. (2019). Higher Education Reforms in Finland: From a Ponderous to a More Agile System?. In Higher Education System Reform (pp. 67-77). Brill Sense.

[51] Williams, H. T., McMurray, J. R., Kurz, T., \& Lambert, F. H. (2015). Network analysis reveals open forums and echo chambers in social media discussions of climate change. Global environmental change, 32, 126-138.

[52] Wong, I. A., Ma, E., Chan, S. H. G., Huang, G. I., \& Zhao, T. (2019). When do satisfied employees become more committed? A multilevel investigation of the role of internal service climate. International Journal of Hospitality Management, 82, 125-135.

[53] World Bank. Higher Education. (2017). Online Available from https://www.worldbank.org/en/topic/tertiaryeducation. 